\title{
DESAFIOS DOCENTE NO ENSINO DE CIÊNCIAS NATURAIS: O USO DE RECURSOS TECNOLÓGICOS E PENSAMENTO CRÍTICO DISCENTE NO ENSINO FUNDAMENTAL, EM CAMETÁ-PA.
}

\author{
Autora: Jelvânia Batista Lopes ${ }^{1}$ \\ CPF: 578.720.072-15 \\ CEP : 68400-000/CAMETÁ/PARÁ \\ TELEFONE: (91) 99195-3860
}

\section{Resumo:}

A pesquisa buscou analisar os desafios docente no ensino de ciências naturais: o uso de recursos tecnológicos e pensamento crítico discente no ensino fundamental, em Cametá-Pa. A formação inicial e continuada no ensino de Ciências requer investigações nas escolas, e assim possibilitar a contribuição não só na parte do âmbito profissional como também, informar que este levantamento dará suporte ao estudo direcionando o pesquisador a inserção gradualmente no campo de estudo, respeitando as posturas individuais dos membros envolvidos. Nesta perspectiva, objetivou identificar os desafios da prática docente no ensino de Ciências no direcionamento da teorização e da prática perante a formação dos discentes no espaço escolar; relatar a prática da pesquisa através do uso tecnológico enquanto metodologia de ensino que promova a formação do aluno enquanto sujeito pesquisador e produtor do seu conhecimento. Logo, utilizou-se como elementos metodológicos: o método qualitativo (quali) e quantitativa (quanti), estudo de campo, com método não experimental, enfoque quali direcionado pelo alcance exploratório analítico. Os dados coletados estão organizados e interpretados usando a logística percentual e numérica para elucidar os valores coletados. Para sustentar e reforçar este significativo trabalho buscou-se as teorias de Lüdke e André (1986); Fazenda (2007); Chizzotti (2007); Falsarella (2004); Freire (1996) e dentre outros. Portanto, evidencia-se na pesquisa a necessidade da formação e o aperfeiçoamento dos docentes quanto ao uso das tecnologias da informação e comunicação, com isso não basta à escola adquirir recursos tecnológicos e materiais pedagógicos sofisticados e modernos, mas os professores limitarem-se apenas ao treinamento para o uso destes. O professor deve, então, averiguar as metodologias de ensino que são utilizadas para promover o desenvolvimento do pensamento crítico do aluno pesquisar, conhecer o que as novas tecnologias têm a oferecer a fim de tornar suas aulas mais instigantes, criando condições de aprendizagem por meio de recursos computacionais, dentre os quais se destacam os aplicativos de programas para produção de textos, planilhas, gráficos, jogos educativos, internet, entre outros.

Palavras-chave: Prática docente no ensino de Ciências. Recurso tecnológico. Formação do pensamento crítico discente.

\footnotetext{
${ }^{1}$ Graduada em Ciências Naturais pela Universidade Estadual do Maranhão (UEMA). Pós-Graduada em Gestão e docência na educação básica pela Fundação Castelo Branco. Pós-Graduada em Ensino de Biologia, pela Faculdade de Patrocínio - FAP. Graduanda em Segunda Licenciatura em Pedagogia pelo Centro Universitário Internacional (UNINTER). Mestranda em Ciências da Educação pela Facultad Interamericana de Ciências Sociales. E-mail: jelvaniatenbat@yahoo.com.br.
} 


\section{INTRODUÇÃO}

O propósito deste trabalho é direcionar novas reflexões e possibilitar ações que viabilize ao professor construir uma identidade profissional que lhe garanta uma ação docente eficaz, mas coerente com as exigências do ensino de Ciências Naturais. Enquanto eixo temático destaca-se os desafios docente no ensino de ciências naturais: o uso de recursos tecnológicos e pensamento crítico discente no ensino fundamental, em Cametá-PA. É importante enfatizar que toda pesquisa será embasada em referencial teórico e prática que dará subsídio não apenas da perspectiva epistemológica, mas também ressaltam práticas presentes que envolvem a ação do aluno e do docente.

Logo, a relevância pessoal deste estudo está na necessidade de formação uma vez que a formação inicial e continuada no ensino de Ciência Natural requer investigações nas escolas, pois leva-nos como pesquisador perceber a necessidade sobre a importância do tema, por se trabalhar no espaço de pesquisa e apoio ao desenvolvimento científico no município, e assim contribuir não só na parte do âmbito profissional, mas também, informar que este levantamento dará suporte ao estudo direcionando o pesquisador a inserção gradualmente no campo de estudo, respeitando as posturas individuais dos membros envolvidos.

A pesquisa se concretizou a partir da prática docente enquanto professora de Ciências Natural, o interesse deste estudo surgiu pelas inquietações vivenciadas como professora, passando por uma série de desafios, os quais incluem acompanhar as descobertas científicas e tecnológicas, constantemente manipulados e inseridos no cotidiano, disponibilizando-as de forma acessível aos alunos.

Além disso, para muitos educadores, tais desafios são agravados por deficiências em suas licenciaturas, visto que, toda problemática circula em um ambiente em que acaba apresentando fatores que prejudicam o bom andamento de ações a serem desempenhadas. Neste caso, o olhar se estende ao campo educacional, mais especificamente para área do ensino de Ciências Naturais, buscando conhecer os processos que desencadeiam essa atuação em termo da formação do pensamento crítico do aluno.

Assim, investigar sobre a pesquisa e formação no aspecto pedagógico de professores virá enfatizar alguns conhecimentos a respeito de uma investigação com profissionais dentro da área que atua, pois se faz necessário as vivências de sala de aula, fundamental lugar que propícia o estudo de campo dentro da área de pesquisa, considerando alguns aspectos presentes na atuação do professor, que perpassa o âmbito da formação profissional como pesquisador. 
Neste sentido, a pesquisa se tornará relevante no espaço pedagógico quando se pretende investigar qual a importância da prática da pesquisa na formação docente, diante do propósito aos anseios que temos na área de Ciência Natural como ciência de conhecimento comum, a qual visa à qualidade do processo ensino aprendizagem dos discentes no espaço escolar.

Ressalta-se que toda pesquisa ocorre em um ambiente que precisa ser descrito para melhor compreensão da mesma, assim a contextualização da problemática centra-se no campo educacional, locado no município de Cametá, zona urbana. Para melhor compreensão da pesquisa de campo destaca-se a Escola Municipal de Ensino Infantil e Fundamental "Santa Terezinha" localizada na Travessa Fleurides de Farias Bangoin, nº 600, Bairro Nova Cametá.

Portanto, este trabalho, foi organizado em três capítulos sendo eles:

O capítulo 1, intitulado "Os desafios docente no ensino de ciências naturais", evidenciando na linha epistemológica a importância da atuação do docente no Ensino de Ciências Naturais perpassando pelos avanços e desafios que estes enfrentam no processo de formação do discente nas redes públicas de ensino.

No capítulo 2, intitulado "A importância da tecnologia para a formação discente no ensino de ciências naturais", destaca-se a importância de se utilizar os aparatos tecnológicos no ambiente no ambiente formativo principalmente no ensino de Ciências, em que os aparatos tecnológicos sejam utilizados como ferramenta de descoberta pelos alunos, possibilitando a eles uma pesquisa através da experiência da ação em campo.

E por fim, no capítulo 3, intitulado "Métodos e Análise conclusiva do objetivo específico identificar os desafios enfrentados pelos docentes no ensino de ciências naturais no direcionamento da teorização e da prática perante a formação dos discentes no espaço escolar”, neste apresenta-se o resultado do primeiro objetivo da pesquisa, análise e intepretação dos dados, além da conclusão final.

\section{OS DESAFIOS DOCENTE NO ENSINO DE CIÊNCIAS NATURAIS.}

A atual Lei de Diretrizes e Bases da Educação Nacional, Lei nº 9.394/96, no artigo 59, preconiza que os sistemas de ensino devem assegurar aos alunos currículo, métodos, recursos e organização específicos para atender às suas necessidades; assegura a terminalidade específica àqueles que não atingiram o nível exigido para a conclusão do ensino fundamental, em virtude de suas deficiências; e assegura a aceleração de estudos aos superdotados para 
conclusão do programa escolar. Também define, dentre as normas para a organização da educação básica.

A possibilidade de avanço nos cursos e nas séries mediante verificação do aprendizadoll (art. 24, inciso V) e "[...] oportunidades educacionais apropriadas, consideradas as características do alunado, seus interesses, condições de vida e de trabalho, mediante cursos e exames (art. 37), (BRASIL, 1999, p. 3).

Hoje, o país vive uma realidade na qual a educação infelizmente não se encontra em primeiro lugar para a população. A concepção de educação na atualidade já é bem diferente de alguns anos atrás, o processo de melhoria é lento, mas caminha - se para atingir uma educação de qualidade para "todos". E é nessa perspectiva que todo profissional da educação deve trabalhar, sempre com o objetivo de atingir o melhor resultado, focando no aprendizado do educando, sendo este aprendizado o processo. Buscando formas, meios, conhecimentos e novas práticas para que o melhor atinja todos, sem exceção. Com esse foco percebe-se e constata-se a importância da pesquisa na educação.

Por muito tempo, o fenômeno educacional foi estudado como algo que pudesse ser isolado, como se as variáveis que o compõem também pudessem ser isoladas, com intuito de se constatar a influência que essas variáveis exerceriam sobre o fenômeno. Por esse motivo, acreditou-se na possibilidade de se decomporem os fenômenos educacionais em suas variáveis básicas, cujo estudo analítico e quantitativo levaria ao conhecimento total desses fenômenos.

Todavia Lüdke e André (1986) enfatizam que nos últimos anos, começaram a surgir sinais de insatisfação entre os pesquisadores a respeito das metodologias empregadas, assim como os resultados das pesquisas educacionais desenvolvidas até então. Esse sentimento de insatisfação não se fez presente apenas entre os teóricos brasileiros, mas também entre os americanos, em que as pesquisas em educação se encontravam bem mais desenvolvidas. Era o momento de romper com o antigo paradigma e buscar novos caminhos que atendessem as necessidades dos pesquisadores do contexto educacional.

$\mathrm{Na}$ tentativa de suprir algumas das lacunas evidenciadas nas pesquisas até então desenvolvidas, e para responder a algumas das questões atuais da pesquisa educacional, começaram a surgir métodos de investigação e abordagens diferentes daquelas empregadas tradicionalmente, influenciadas agora, por uma proposta que, conforme elucida Lüdke e André (1986) colocam o pesquisador no meio da cena de investigação, participando dela e tomando partido, pois os questionamentos nascem de uma curiosidade investigativa revelados pela própria prática educacional. Assim, surgem a pesquisa etnográfica, o estudo de caso e os 
chamados modelos alternativos de pesquisa, em que se destacam a pesquisa participante, a pesquisa-ação e a pesquisa colaborativa.

Fazenda (2007) aponta que as pesquisas que estão sendo realizadas no âmbito educacional servem como "bons instrumentais", já que favorecem o repensar de outras práticas. As mais adequadas a esse propósito são aquelas que possibilitam novas interpretações, novos caminhos a serem pesquisados. Esse avanço teórico impulsiona as novas buscas para os problemas da prática pedagógica, sobre novos olhares teóricos e metodológicos.

Entre outros tipos de pesquisa utilizadas na área da educação, destacam-se os estudos que focalizam as situações específicas do cotidiano escolar. No entanto, apenas por volta dos anos 1950 e 1960 é que essas pesquisas passam a ter a sua importância, voltando-se para a valorização da subjetividade e crítica da razão instrumental. Assim, há uma renovação teórico metodológica e temática, com um crescimento significativo de pesquisas empíricas, e ênfase nos métodos qualitativos, entrando em cena o interacionismo simbólico, com a fenomenologia de Schutz e a dialética. Conforme argumenta Chizzotti (2007), a proposta apresentada por Schutz era compreender o mundo visto a partir da vida cotidiana e as rotinas que estruturavam a vida social dos sujeitos.

Neste contexto vale ressaltar a importância do pesquisador, seu papel em diferentes contextos e em diferentes situações. Ele deve considerar o seu entorno, ao elaborar a proposta de pesquisa, e compreender que, em cada contexto onde a pesquisa for aplicada, os resultados obtidos serão os mais diversos possíveis.

Outro aspecto que cabe destacar é o nível de envolvimento com a pesquisa científica, em que muitas vezes, se encontra o aluno que retorna à formação continuada, aluno esse que esteve fora há tempos do sistema educacional na condição de aluno e que tem dificuldade em compreender como se configura uma pesquisa, um estudo sistematizado, uma investigação contextualizada.

No sentido mais estrito do termo pesquisa, visando à criação de um corpo de conhecimento sobre certo assunto, Gadotti (2000, p. 16) ressalta

\footnotetext{
O Brasil obteve como um dos piores indices de educação em ciências, na avaliação das nações unidas (ONU), realizado pela UNESCO-2018. Sendo que a forma de ensinar ciências estava relacionada com apresentação do conhecimento cientifico como um conhecimento estático, decorativo e repetitivo, a prática dos professores era baseada interamente no livro didatico, na aula expositiva como técnica predominante, o uso quadro e pincel, sem uso de materiais didáticos alternativos e métodos mais diversificados.
}

Quando pensamos o ensino de Ciências naturais na atualidade, a primeira palavra que nos surge à mente é: desafios. Isso porque a realidade complexa impõe dificuldades àqueles 
que pretendem adentrar-se pelos caminhos da educação científica. Por outro lado, a Didática das Ciências nas últimas décadas tem se constituído uma profícua área de pesquisa, cujos principais resultados podem orientar aos professores de Ciências no enfrentamento desses desafios da prática. Objetiva-se, nessa pesquisa, refletir a respeito da formação inicial e/ou continuada dos professores, seus desafios no ensino de Ciências no mundo contemporâneo e na forma como orientam seus alunos na construção do conhecimento científico.

Falsarella (2004) comenta a formação de professores como um contínuo de desenvolvimento que começa com a formação inicial e acompanha o professor em toda sua trajetória profissional. Nesse sentido, a formação continuada não pode ser entendida como algo dicotômico à formação inicial, uma vez que, em tempos de mudanças rápidas e contínuas, nenhum profissional pode ficar desatualizado em sua trajetória. Na verdade, a formação docente pode ser vista como um quebra-cabeça nunca finalizado, cujos limites encontram-se permanentemente em aberto

\section{A IMPORTÂNCIA DA TECNOLOGIA PARA A FORMAÇÃO DISCENTE NO ENSINO DE CIÊNCIAS NATURAIS.}

As tecnologias podem ser e devem ser inseridas no cotidiano do ambiente escolar. Fazse referência como o professor pode agir no sentido de aliar as novas tecnologias às metodologias utilizadas em sala de aula, como forma de melhorar os processos de ensino e de aprendizagem. Enfoca o fato dos alunos do hoje já crescerem informatizados, o que torna imprescindível para educação que os professores e demais profissionais se qualifiquem quanto ao processo de inserir ao ensino. Nesse sentido de que as novas tecnologias sejam vistas como mais uma ferramenta de auxílio ao processo de educação, como dinamizadora do processo de ensino e como instigadoras para a melhoria da aprendizagem. Para tanto, adota-se como objetivo geral: Refletir sobre o uso das novas tecnologias para a melhoria dos processos de ensino e de aprendizagem.

Antes de introduzir as novas mídias interativas nas aulas expositivas é preciso entender suas funcionalidades e as consequências de seu uso, pois somente a partir desse momento é possível utilizá-las de forma a transformar as aulas em eventos de discussão onde ocorra de maneira efetiva à participação de todos os indivíduos, bem como professores, alunos e pesquisadores, propiciando assim a comunicação que só é possível a partir do momento que todas as partes se envolvem. 
Para que os recursos tecnológicos façam parte da vida escolar é preciso que alunos e professores o utilizem de forma correta, e um componente fundamental é a formação e atualização de professores, de forma que a tecnologia seja de fato incorporada no currículo escolar, e não vista apenas como um acessório ou aparato. É preciso pensar como incorporá-la no dia a dia da educação de maneira definitiva. Depois, é preciso levar em conta a construção de conteúdos inovadores, que usem todo o potencial dessas tecnologias.

O processo de incorporação das tecnologias nas ações docentes guia professores e alunos para uma educação libertadora e humanista, na qual homens e mulheres imergem na construção do conhecimento, se tornando sujeitos da condução de sua própria aprendizagem, ou seja, um sujeito participativo e responsável pela sua própria construção, deixando de lado o sujeito passivo para se tornar autônomos e cidadãos democráticos do saber, a esse respeito Freire enfatiza que:

\begin{abstract}
A educação é uma resposta da finitude da infinitude. A educação é possível para o homem, portanto esse é inacabado. Isso leva a sua perfeição. A educação, portanto, implica uma busca realizada por um sujeito que é o homem. O homem deve ser sujeito de sua própria educação. Não pode ser objeto dela. Por isso, ninguém educa ninguém. (FREIRE, 1979, p. 27)
\end{abstract}

Enfim, para que todo esse leque de oportunidades aconteça seja vivenciado, é preciso que professor e aluno andem juntos, trabalhem num mesmo ritmo de cooperatividade, principalmente falem a mesma língua que é a da era da informação, pois somente trabalhando os interesses será possível um aprendizado de forma gratificante e com resultados positivos para ambos os envolvidos no ensino-aprendizagem.

Ao se observar e analisar a linha do tempo da revolução tecnológica percebemos os significativos avanços em todos os aspectos da sociedade, não se podendo negar que estas transformações influenciaram no comportamento de pessoas, seus juízos de valores e crenças, repercutindo por todos os segmentos que estruturam a sociedade. A tecnologia tornou-se sinônimo de poder, alterando comportamentos, a economia, a política, o ambiente e até a cultura de um determinado povo, gerando uma verdadeira transformação social.

É certo, que o uso de tecnologias pelas sociedades, ao longo da história da humanidade, principalmente na Idade Moderna, no período das revoluções industriais, foi o propulsor para a definição de uma sociedade capitalista, voltada principalmente para obtenção de lucro capital e menos valorização do bem-estar social, como se pode observar.

A partir disso o homem foi criando tecnologias de acordo com suas necessidades e usando-as para a dominação do poder. Hoje, as grandes potências mundiais aperfeiçoam as novas tecnologias e começam a utilizá-las para as guerras, envolvendo as relações de poder e 
inovações tecnológicas. Portanto, somente o próprio ser humano será capaz de direcionar o uso da tecnologia de forma correta. Pois ele através da tecnologia e do conhecimento é capaz de destruir a própria humanidade ou construir possibilidades de viver melhor como produzir descobertas de cura para doenças, remédios, aparelhos capazes de salvar vidas, entre muitos outros feitos.

\section{MÉTODOS E ANÁliSE CONCLUSIVA: DESAFIOS ENFRENTADOS PELOS DOCENTES NO ENSINO DE CIÊNCIAS NATURAIS NO DIRECIONAMENTO DA TEORIZAÇÃO E DA PRÁTICA PERANTE A FORMAÇÃO DOS DISCENTES NO ESPAÇO ESCOLAR.}

A investigação reflete uma espécie de diálogo entre os investigadores e os sujeitos do estudo no modo como diferentes pessoas dão sentido às suas vidas; no que as pessoas experimentam; como interpretam suas experiências e como estruturam o mundo social em que vivem. Segundo Martinelli (1999) é trazer à tona o que os participantes pensam a respeito do que está sendo pesquisado. Não é só a visão de pesquisador que é importante, mas também o que o sujeito tem a dizer em relação ao problema.

Este estudo foi assistido pela investigação quali e quanti, pois a pesquisa terá seu peso maior com o método qualitativo a pesquisa qualitativa que segundo Oliveira (2005), é um processo de reflexão e Análise da realidade, o qual implica o uso de observações, aplicação de questionários, entrevista e análise de dados.

Sendo assim, a pesquisa foi traçada diante da investigação direta, uma vez que o pesquisador esteve diretamente no campo de estudo recoletando os dados necessários para este estudo, chamada também de investigação com dados primários Padilha (2014).

Nesta pesquisa as fontes de dados foram coletadas diante dos sujeitos (as amostras que participaram desta pesquisa distribuídas nas categorias docente, categoria dos diretores e categoria dos coordenadores pedagógicos e categoria discente) que emitiram suas opiniões e ideias diante das respostas dadas para o pesquisador frente a aplicação dos instrumentos que serviram para coletar os dados deste estudo.

O sujeito de estudo pode consistir em pessoas ou grupos de pessoas que serão estudadas no ambiente de investigação relacionadas com as variáveis em estudos. Portanto, a pesquisa está voltada ao âmbito educacional, no município de Cametá visando compreende a relação das variáveis, o universo pode ser compreendido por toda rede municipal de educação de Cametá, 
uma vez que o universo ou lugar tem a finalidade de definir o tempo, o lugar, o espaço onde ocorrerá a pesquisa.

Quadro 2 - Amostra

\begin{tabular}{|l|c|c|c|c|}
\hline \multicolumn{1}{|c|}{ Sujeitos } & Professores & Coordenadores & Equipe gestora & Alunos \\
\hline População & $\begin{array}{c}17 \text { do } 6^{\mathbf{0}} \text { ao } 9^{\mathbf{0}} \\
\text { ano }\end{array}$ & 02 & 03 & 765 \\
\hline Amostra & 07 & $02=100 \%$ & $03=100 \%$ & 207 \\
& $\begin{array}{l}\text { Somente os de } \\
\text { Ciências }\end{array}$ & & $6^{\mathbf{0}}$ ao $9^{\mathbf{o}}$ ano \\
\hline Unidade de análise & $\begin{array}{l}\text { E.M.E.I.F. SANTA TEREZINHA } \\
\text { OBS.: }\end{array}$ \\
\hline
\end{tabular}

Conclui-se que o ensino de Ciências é importante, pois é vista como positiva pelas categorias docentes, coordenação e gestão $100 \%$, assim como os discentes $76 \%$ que afirmam o ensino de ciências contribuir para a formação global do aluno, pensamento crítico do aluno, a formação cidadã do aluno, para que o ele consiga ingressar no nível superior através do ENEM. Mas, 24\% dos discentes diz que o ensino de ciências contribui para a formação cidadã do aluno. Diante do que foi exposto, o ensino de ciências é importante na formação dos discentes de modo a contribuir para uma aprendizagem significativa, prazerosa e dinâmica. Conforme Moran (2000, p. 23):

um dos grandes desafios para o educador é ajudar a tornar a informação significativa, a escolher as informações verdadeiramente importantes entre tantas possibilidades, a compreendê-las de forma cada vez mais abrangente e profunda e a torná-las parte do nosso referencial (MORAN, 2000, p. 23).

Evidenciou-se nas práticas utilizadas para trabalhar Educação Ambiental, os docentes 57\% afirmam há necessidade de aulas assessoradas por recursos tecnológicos, assim como 87\% dos discentes, como também a gestão com $67 \%$ vê a necessidade do uso desse recurso nas práticas pedagógicas. Logo, a coordenação com 100\% atribui a utilização das aulas a campo com experimentos. Por fim, destaca-se ainda os docentes com $43 \%$ e a gestão com $33 \%$ onde pontua que a finalidade da educação esteja estabelecida em prol de uma formação ao discentes.

Sobre as dificuldades apontada no Ensino de Ciências apresentam-se em termo das categorias docentes com $57 \%$ e a gestão $100 \%$ como os discentes $100 \%$, fica nítida a afirmação metodologia consistir em um grande problema do ensino aprendizagem. Já que os docentes 
com $43 \%$ e coordenação com $100 \%$ pontuaram que a prática desenvolvida dificulta o avanço da qualidade da educação.

Demo (2006) aponta que para o aluno aprender bem, é imprescindível que o professor continue aprendendo bem, sendo um eterno aprendiz. No entanto, alerta para que o professor desenvolver sua própria aprendizagem não basta apenas acumular certificados ou semanas pedagógicas, é necessário que esse investimento seja capaz de provocar 7 mudanças no fazer pedagógico em sala de aula, refletindo na aprendizagem de qualidade dos alunos.

Referente aos resultados obtidos nas categorias ao ensino de ciências previsto no planejamento escolar, valorizando as categorias docente, coordenação, gestão e discentes afirmam 100\% que conteúdo é aplicado nas aulas no Ensino Ciências Naturais.

A respeito da participação dos alunos nas aulas de ciências, ocorre de forma satisfatório na categoria docente $71 \%$, assim a coordenação com $100 \%$, mas fica evidente na categoria discentes com $4 \%$ que não à participação do aluno nas aulas de ciências. Portanto, ao analisar categoria gestão $100 \%$, docentes com $29 \%$ e os discentes $96 \%$ afirmam pouco satisfatório. O que mostra que os educandos não estão atuando em sala de aula.

\begin{abstract}
Os alunos por crescerem em uma sociedade permeada de recursos tecnológicos, são hábeis manipuladores da tecnologia e a dominam com maior rapidez e desenvoltura que seus professores. Mesmo os alunos pertencentes a camadas menos favorecidas têm contato com recursos tecnológicos na rua, na televisão, etc., e sua percepção sobre tais recursos é diferente da percepção de uma pessoa que cresceu numa época em que o convívio com a tecnologia era muito restrito (ALMEIDA, 2000, p. 108).
\end{abstract}

Diante da análise, as atividades de ciências se constituem como atividades de aprendizagem significativas e contextualizadas, os entrevistados docentes, coordenação e gestão marcaram $100 \%$, logo os discentes com $81 \%$ afirmam que sim. Verifica-se que a aplicabilidade das atividades na disciplina de ciências naturais.

Sendo assim, as habilidades apresentadas pelos alunos no ensino de Ciências são mediantes as categorias docentes, coordenação, gestão e discentes $100 \%$ afirmam satisfatório para aprendizagem do educando. Gadotti (2000, p. 251), descreve:

Hoje, o importante na formação do trabalhador (também do trabalhador em educação) é saber trabalhar coletivamente, ter iniciativa, gostar do risco, ter intuição, saber comunicar-se, saber resolver conflitos, ter estabilidade emocional (GADOTTI, 2000, p. 251).

Assim, os alunos gostam da maneira como é ministrada as aulas de Ciências, os docentes com $71 \%$ e os coordenadores $100 \%$ assim a gestão $100 \%$ e os discentes $66 \%$, afirmam que sim. Isso mostra que as aulas estão sendo ministradas de maneira que o aluno entenda. 
Para ambas as categorias que traz informações sobre formação profissional específica para ensino de ciências, os docentes, coordenadores e gestão 100\% afirmam Sim, jornadas, oficinas e palestras. Além disso, é importante ressaltar que a formação docente é incessante, ou seja, não tem fim, e acontece todos os dias, em cada sala de aula e em contato com cada indivíduo. Freitas e Villani (2002, p. 43) afirmam que:

\begin{abstract}
é necessário um novo perfil de formação, que seja capaz de vencer os desafios mais urgentes de uma sociedade "multimídia e globalizada", em que o rápido desenvolvimento, científico e tecnológico, impõe uma dinâmica de permanente reconstrução de conhecimento, saberes, valores e atitude (FREITAS e VILLANI, 2002, p. 43).
\end{abstract}

Aliar os novos recursos, as aulas práticas e com experimento são importantes para que o aluno tenha uma aprendizagem mais significativa as categorias docentes, coordenação, gestão e discentes $100 \%$ afirmam sim, pois os recursos podem ser utilizados no sentido de melhorar o processo de ensino e aprendizagem.

Ressaltamos que os recursos são utilizados nas aulas de ciências, os docentes $43 \%$ e os coordenadores $50 \%$, desse modo a gestão $33 \%$, os discentes $32 \%$ optaram por data show, slides, DVD e Tv, sendo que a maioria das categorias afirmam que utilizam lousa, apostilas e livro didático com frequência.

Evidenciou-se que os recursos tecnológicos contribuem para a aprendizagem significativa e contextualizada no ensino de Ciências, pois os entrevistados docentes, coordenadores gestão e discentes $100 \%$ afirmam sim, é notável a importância do uso de tecnologia em sala de aula e a discussão sobre esta para a sociedade. Entretanto, o uso deve ser feito de forma consciente e orientado pelo docente, que muitas vezes não possui uma formação adequada para tal. Segundo Moran (2007, p. 67):

\footnotetext{
as tecnologias se constituem em pontes que abrem a sala de aula para o universo, além de serem formas de representação da realidade, seja de forma mais abstrata ou concreta, mais estática ou dinâmica, mais linear ou paralela, mas todas elas combinadas e integradas, possibilitando assim uma melhor apreensão da realidade, além de favorecer o desenvolvimento de todas as potencialidades do discente (MORAN, 2007, p. 67).
}

De acordo, a pesquisa através da internet é um mecanismo que contribui positivamente para a construção do pensamento crítico do discente, os entrevistados docentes, $71 \%$, coordenação, gestão $100 \%$ e discentes $61 \%$ afirmam sim. Observa-se a importância de aliar-se ao uso da internet e dos novos recursos tecnológicos que estão surgindo à atividade pedagógica pode significar dinamismo, criatividade e interação não só de conhecimentos teóricos, mas daqueles relacionados à vida dos estudantes. 
Porém é necessário um uso com cautela das tecnologias, como afirma Araújo (2005, p.23):

O valor da tecnologia na educação é derivado inteiramente da sua aplicação. Saber direcionar o uso da Internet na sala de aula deve ser uma atividade de responsabilidade, pois exige que o professor preze, dentro da perspectiva progressista, a construção do conhecimento, de modo a contemplar o desenvolvimento de habilidades cognitivas que instigam o aluno a refletir e compreender, conforme acessam, armazenam, manipulam e analisam as informações que sondam na Internet.

Conclui-se com frequência o profissional no ensino de Ciências Naturais se utiliza da pesquisa para promover em seu aluno a construção do conhecimento, sendo ele agente pesquisador e construtor do saber. Portanto, as categorias docentes, coordenadores, gestão e discentes $100 \%$ afirmam semanalmente, pois apontam para a importância da pesquisa de recursos e uso de metodologias variadas e diversificada, que possam estimular o aluno para a participação dinâmica e criativa, potencializando o aprendizado. Libâneo (1998) considera que essas resistências existem, por não serem trabalhadas nos processos de formação inicial e contínua do professor e, este fator poderia ocorrer a partir da integração de novas tecnologias aos currículos, desenvolvendo habilidades e formação de atitudes favoráveis ao emprego destas tecnologias.

\section{CONSIDERAÇÕES FINAIS}

Diversos são os fatores considerados importantes para que o professor de ciências naturais cumpra seu papel frente à sociedade e seus alunos. A pesquisa propôs analisar os desafios do docente no ensino de ciências naturais no uso de recursos tecnológicos para desenvolvimento do pensamento crítico do discente nos anos finais do ensino fundamental no município de Cametá, no período de 2019.

Tiveram como finalidade, sensibilizar os professores, bem como fazer uso das tecnologias e multiplicar conhecimentos adquiridos. De acordo com a troca de experiências, a entrevista, fica evidente que é muito importante fazer uso das tecnologias e comunicação para o processo de ensino e aprendizagem e, que o professor deve buscar, pouco a pouco, dominar as tecnologias e não deixar dominar por elas.

É importante que o professor tenha conhecimento sobre tecnologia hoje disponibilizadas nas escolas e também que o uso desse recurso oferece oportunidades tanto para alunos quanto para professores e que, a utilização bem planejada desses recursos pode ocasionar vantagens 
para os envolvidos. Sendo assim, é de extrema importância a aplicação desses recursos na sala de aula, pois eles irão contribuir para que os alunos se interessem pelos conteúdos, facilitando o entendimento sobre os assuntos das disciplinas, contribuindo para o processo de ensino aprendizagem, que irá garantir uma sala de aula dinâmica, e mudanças significativas na prática pedagógica.

Conclui-se que os professores de Ciências Naturais cumpram seu papel frente à sociedade e seus alunos, cujos educadores precisam levar em conta a ressignificação da sua prática, como um dos meios constitutivos da construção de novos saberes profissionais. Conduzindo aos discentes a inovação ao uso da tecnologia para que os estudantes possam aprender a pesquisar e analisar.

Através deste trabalho, conclui-se que o professor precisa identificar os desafios enfrentados e buscar conhecer e estar consciente da sua prática docente no processo educacional / pedagógico, conduzindo para a apropriação de conhecimentos. Para que a sala de aula se torne um espaço de aprendizagens significativas, torna-se necessário que os dois atores, professor e aluno, estejam presentes e atuantes, desencadeando o processo de ensino e aprendizagem.

Através dos relatos dos professores entrevistados, a importância do uso das tecnologias, pelo aumento do interesse, participação e motivação dos alunos, a aula produtiva e dinâmica, facilitando a problematização dos conteúdos. Para um uso significativo das tecnologias, que traga resultados no processo de ensino e de aprendizagem.

Evidencia-se na pesquisa a necessidade da formação e o aperfeiçoamento dos docentes quanto ao uso das tecnologias da informação e comunicação. Não basta à escola adquirir recursos tecnológicos e materiais pedagógicos sofisticados e modernos, mas, os professores limitarem-se apenas ao treinamento para o uso destes.

Portanto, faz-se necessário na educação, construir novas concepções pedagógicas elaboradas sob a influência do uso dos novos recursos tecnológicos que resultem em práticas que promovam o currículo nos seus diversos campos dentro do sistema educacional. Desta forma, os recursos tecnológicos podem contribuir no processo de ensino e aprendizagem, promovendo uma educação mais estimuladora, ganhando destaque enquanto recurso pedagógico.

O professor deve, então, averiguar as metodologias de ensino que são utilizadas para promover o desenvolvimento do pensamento crítico do aluno pesquisar, conhecer o que as novas tecnologias têm a oferecer a fim de tornar suas aulas mais instigantes, criando condições de aprendizagem por meio de recursos computacionais, dentre os quais se destacam os aplicativos de programas para produção de textos, planilhas, gráficos, jogos educativos, 
internet, entre outros. Isto significa que, ele deve deixar de ser o repassador dos conhecimentos e passar a ser o criador de ambientes de aprendizagem, facilitando o processo de desenvolvimento intelectual do aluno.

\section{REFERÊNCIAS}

ALMEIDA, Maria Elisabeth Bianconcini de. ProInfo: Informática e Formação de Professores. vol. 1. Série de Estudos Educação a Distância. Brasília: Ministério da Educação, Seed, 2000b.

ARAÚJO, Ulisses F.; PUIG, Josef Maria. Educação e valores: pontos e contrapontos. Valéria Amorim Arantes (org.). São Paulo: Summus, 2005.

BRASIL. Constituição da República Federativa do Brasil de 1988.

. Lei $\mathrm{n}^{\circ} 9394$ de 20 de dezembro de 1996. Estabelece as Diretrizes e Bases da Educação Nacional. Diário Oficial da União. Brasília, nº 248, 1996.

. Secretaria de Educação Fundamental. Parâmetros Curriculares Nacionais: Ciências

Naturais/Secretaria de Educação Fundamental. Brasília: MEC/SEF, 1998. http://portal.mec.gov.br/seb/arquivos/pdf>. Acesso em 12 de agosto de 2013.

. Ministério da Educação - MEC, Secretaria de Educação Média e Tecnológica -

SEMTEC. Parâmetros Curriculares Nacionais para o Ensino Médio. Brasília, MEC/SEMTEC, 1999, 4 v (versão baixada do site do MEC).

Editora MS, 2006.

MINISTÉRIO DA SAÚDE. Estatuto da Criança e do adolescente. 3. ed. Brasília:

. MEC. Guia de tecnologias educacionais. Brasília: Ministério da Educação, Secretaria de Educação Básica, 2009. Disponível em: <http://jornalescolar.org.br/portal/images/PDF/guia\%20mec\%20tecnologias\%20educacio nais\%202008.pdf $>$. Acesso em: 28 de janeiro de 2013.

MEC/SEF, 2010.

Diretrizes Curriculares Nacionais da Educação Básica: CNE/CEB nº 4. Brasilia:

. Presidência da República. LDB: Lei de diretrizes e bases da educação nacional. Brasília: Senado Federal, Coordenação de Edições Técnicas. 2017.

CHIZZOTTI, A. O cotidiano e as pesquisas em educação. In: FAZENDA, I. Novos enfoques da pesquisa educacional. 6. ed. São Paulo: Cortez, 2007.

DEMO, Pedro. Metodologia científica em ciências sociais. 3. ed. rev. e atual. São Paulo, SP: Atlas, 1995.

. Estudar. 2006: Disponível em: http://pedrodemo.blog.uol.com.br/

FAZENDA, I. (Org.). A pesquisa como instrumentalização da prática pedagógica. In: SEVERINO, A. J. et al. Novos enfoques da pesquisa educacional. 6. ed. São Paulo: Cortez, 2007.

FALSARELLA, Ana Maria. Formação continuada e prática na sala de aula: os efeitos da formação continuada na formação do professor. Campinas: Autores Associados, 2004.

FREITAS, D.; VILLANI, A.; Formação de professores de ciências: um desafio sem limites. Revista Investigações em Ensino de Ciências- V7(3), pp. 215-230, 2002. 
FREIRE, P.; SHOR, I. 1993. Medo e Ousadia. Rio de Janeiro, Paz e Terra. Educação e Mudança. 25 ed. Rio de Janeiro: Paz e Terra, 1979.

GADOTTI, Moacir. Perspectivas Atuais da Educação. Porto Alegre: Artes Médicas Sul, 2000.

LIBÂNEO, J.C. Adeus Professor, adeus professor? Novas exigências educacionais e profissão docente. 2. ed. são Paulo: Cortez editora,1998.

LÜDKE, Menga e ANDRÉ, Marli E. D. A. Pesquisa em educação: abordagens qualitativas. São Paulo: EPU, 1986.

MARTINELLI, Maria Lúcia. O uso de abordagens qualitativas na pesquisa em serviço social. MARTINELLI, Maria Lúcia (Org.). Pesquisa qualitativa: um instigante desafio. São Paulo: Vers Editora, 1999. (Série Núcleo de Pesquisa; 1).

MEC. Parâmetros curriculares nacionais, terceiro e quarto ciclos do ensino fundamental. Disponível em: portal.mec.gov.br/seb/arquivos/pdf/ciencias.pdf. acesso em 22/dez/2010.

MORAN, José Manuel et al. Novas tecnologias e mediação pedagógica. 6. ed. Campinas: Papirus, 2000.

A integração das tecnologias impressas, eletrônicas e digitais.Debate: Mídias na educação. Boletim 24. Novembro/dezembro de 2006. Disponívelem: $<$ http://www.tvbrasil.org.br/fotos/salto/series/175900Midiaeducacao.pdf $>$. Acesso em: 26de outubro de 2012. As mídias na educação. In: MORAN, J. M. "Desafios na Comunicação Pessoal". $3^{\mathrm{a}}$ ed. São Paulo: Paulinas, 2007, p. 162-166. Disponível em: <htpp://www.eca.usp.br/prof/moran/mídias_educ.htm> Acesso em: 10 jul. 2015.

OLIVEIRA, Maria Marly de. Como fazer pesquisa qualitativa. Recife: Ed. Bagaço, 2005.

PADILHA, R. C. Documentação museológica e gestão de acervo. Florianópolis: FCC, 2014a. 71 p. (Coleção Estudos Museológicos; v.2.). 